\title{
Transmisión ocular del SARS-CoV-2
}

\section{Ocular transmission of SARS-CoV-2}

\author{
Claudia Maldonado-Correa* y Claudia Soto-Idrogo \\ Instituto Nacional de Oftalmología, Lima, Perú
}

\author{
Sr. Editor, \\ En la edición de marzo-abril de 2021, Ruiz Morales \\ realiza una revisión sobre la transmisión ocular para \\ desarrollar COVID-19 ${ }^{1}$, y al respecto planteamos las \\ siguientes consideraciones.
}

EI SARS-CoV-2 es un virus que se transmite a gran velocidad y a la fecha ha producido más de 119,603,761 de infectados, con 2,649,722 muertes en todo el mundo? ${ }^{2}$.

Respecto a la transmisión ocular, las evidencias aún son controversiales. Si bien es cierto que se ha demostrado que en la córnea existen receptores de la enzima convertidora de la angiotensina 2, por lo que los ojos serían un vía de transmisión posible, los estudios revelan que solo el $3 \%$ de los pacientes tienen muestras de hisopado conjuntival positivas para SARS-CoV-2 y se ha reportado que únicamente el $1 \%$ han tenido diagnóstico de conjuntivitis o congestión conjuntival como síntoma inicial ${ }^{3}$. Así mismo, se ha visto que en los pacientes con COVID-19 la presencia de síntomas oculares se ha asociado con marcadores inflamatorios elevados, mas no se correlacionan con manifestaciones clínicas ni de imágenes ${ }^{4}$. Estos datos nos orientan a que, aunque la transmisión es posible, resulta poco probable, y aquellos pacientes con síntomas oculares pueden desarrollar parámetros laboratoriales más elevados, pero son necesarios estudios que lo correlacionen con otras características de gravedad.
Con lo previamente mencionado, podemos indicar que existen otras vías de propagación comprobadas, de las cuales la más frecuente es la aérea, involucrando la propagación del SARS-COV-2 por gotículas respiratorias y aerosoles. Teniendo en cuenta esta premisa, se está tratando de estandarizar las medidas preventivas para disminuir la propagación del virus, entre ellas el lavado frecuente de manos, el distanciamiento social de al menos 1 metro y el uso de mascarillas. Los tipos de mascarillas de las que se dispone actualmente son, en términos generales, de dos tipos: las médicas y las no médicas. Las mascarillas no médicas pueden ser de tela, se recomienda que tengan tres capas y están indicadas para la población general, mientras que las médicas (por ejemplo, los respiradores N95) son para el personal de salud, pero también para las personas con diagnóstico o sospecha de COVID-19, y las actuales recomendaciones de la Organización Mundial de la Salud señalan que aquellas personas con enfermedades debilitantes también podrían utilizarlas; este es un factor importante por ser población de alto riesgo de desarrollar formas graves de la infección ${ }^{2}$. Por otro lado, dada la posible propagación ocular del SARS-COV-2, se podrían usar escudos o protectores faciales, así como también lentes protectores, pero la evidencia aún es incierta. Las actuales recomendaciones se orientan a la vacunación masiva, la cual al momento se viene dando de manera

Correspondencia:

*Claudia Maldonado-Correa

Avda. Universitaria Sur 2095, Dpto. $309 \quad$ Fecha de recepción: 23-03-2021

Fecha de aceptación: 06-04-2021

Disponible en internet: 01-07-2021

15084 Pueblo Libre, Lima, Perú

DOI: 10.24875/RMO.M21000176

Rev Mex Oftalmol. 2021;95(4):177-178

E-mail: clamaco04@gmail.com

0187-4519/@ 2021 Sociedad Mexicana de Oftalmología. Publicado por Permanyer. Este es un artículo open access bajo la licencia CC BY-NC-ND (http://creativecommons.org/licenses/by-nc-nd/4.0/). 
paulatina con las diferentes vacunas que se encuentran en el mercado ${ }^{5}$.

Por los motivos antes expuestos, se debe continuar fomentando la actualización de las posibles medidas para prevenir la COVID-19 y de esta manera desacelerar la propagación de este virus que ha causado hasta el momento una alta morbimortalidad.

\section{Conflicto de intereses}

Los autores declaran que no presentan conflictos de intereses.

\section{Responsabilidades éticas}

Protección de personas y animales. Los autores declaran que para esta investigación no se han realizado experimentos en seres humanos ni en animales.
Confidencialidad de los datos. Los autores declaran que en este artículo no aparecen datos de pacientes.

Derecho a la privacidad y consentimiento informado. Los autores declaran que en este artículo no aparecen datos de pacientes.

\section{Bibliografía}

1. Ruiz-Morales M. La ruta ocular, un riesgo para desarrollar COVID-19. Rev Mex Oftalmol. 2021; 95: 93-4.

2. World Health Organization. Coronavirus (COVID-19) Dashboard. (Consultado el 17 marzo 2021.) Disponible en: https://covid19.who.int/

3. Cao K, Kline B, Ying G, II N. Current evidence of 2019 novel coronavirus disease (COVID-19) ocular transmission: a systematic review and meta-analysis. Biomed Res Int. 2020;2020:7605453.

4. Wu P, Duan F, Luo C, Liu Q, Qu X, Liang L, et al. Characteristics of ocular findings of patients with coronavirus disease 2019 (COVID-19) in Hubei Province, China. JAMA Ophthalmol. 2020;138:575-8.

5. Marra AR, Edmond MB, Popescu SV, Perencevich EN. Examining the need for eye protection for coronavirus disease 2019 (COVID-19) prevention in the community. Infect Control Hosp Epidemiol. 2020;1-2. 